\title{
Features of Primary Healthcare Clinics Associated with Patients' Utilization of Emergency Rooms: Urban-Rural Differences
}

\section{Aspects des cliniques de soins primaires de santé publique associés à l'utilisation plus des services d'urgence - les différences entre les milieux urbains et ruraux}

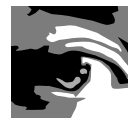

by JEANNIE L. HAGGERTY, PHD Associate Professor

CRC Population Impacts of Health Services

Sciences de la santé communautaire and Médecine familiale, Université de Sherbrooke Longueuil, Québec

DANIÈLE ROBERGE, PHD

Adjunct Professor

Sciences de la santé communautaire

Université de Sherbrooke

Longueuil, Québec

RAYNALD PINEAULT, MD, PHD

Emeritus Professor

Services de la Médecine sociale et préventive

Montréal, Québec 


\title{
Features of Primary Healthcare Clinics Associated with Patients' Utilization of Emergency Rooms
}

DANIELLE LAROUCHE, MSC

Project Coordinator

Centre de recherche de l'Hôpital Charles LeMoyne

Greenfield Park, Québec

\author{
NASSERA TOUATI, PHD \\ Assistant Professor
}

École nationale d'administration publique

Montréal, Québec

\begin{abstract}
Objective: A 2002 survey of primary healthcare sites found that 51\% of rural and 33\% of urban primary care patients reported using the hospital emergency room (ER) in the last 12 months. We did a secondary analysis to identify urban-rural differences in accessibility-related organizational features that predicted ER use.

Methods: We collected information on clinic organization and physicians' practice profiles from 100 primary healthcare sites across Quebec and 2,725 of their regular patients, who reported on ER use. We used hierarchical logistic regression to identify organizational features that predict the probability of ER use by patients.

Results: Patient confidence in rapid access at their clinic decreases ER use $(\mathrm{OR}=0.73)$. Rural sites offer fewer walk-in services or on-site medical procedures and less proximity to laboratory and diagnostic services, but paradoxically, rural patients are more confident that their own physician will see them for a sudden illness. Patients from clinics offering a larger range of medical procedures on site have lower ER use $(\mathrm{OR}=0.92$ per procedure). Rural physicians tend to divide their time between hospital and primary care; doing in-patient care increases $\mathrm{ER}$ use $(\mathrm{OR}=1.64)$.

Discussion: Decreased ER use is found in patients of clinics organized to enhance responsiveness to acute needs, especially in rural areas. Although the high rates of ER use in rural areas partly reflect problems with the accessibility of primary care clinics, in a resource-scarce context rural hospital ERs may cover both primary care urgent problems and emergencies.
\end{abstract}

\section{Résumé}

Objectif: Une enquête réalisée en 2002 auprès de sites de soins de première ligne a révélé que $51 \%$ des patients recevant des soins primaires en milieu rural et $33 \%$ des patients recevant des soins primaires en milieu urbain ont déclaré avoir utilisé le service des urgences d'un hôpital au cours des 12 derniers mois. Nous avons effectué une analyse secondaire pour repérer les différences entre les milieux urbains et ruraux sur 
le plan des caractéristiques organisationnelles reliées à l'accessibilité permettant de prédire l'utilisation des services d'urgence.

Méthodes : Nous avons colligé des informations relatives à l'organisation clinique et aux profils de pratique des médecins de 100 sites de soins de santé primaires dans tout le Québec et pour 2725 de leurs patients réguliers qui ont rapporté sur l'utilisation de l'urgence. Nous avons employé une régression logistique hiérarchique pour cerner les caractéristiques organisationnelles permettant de prédire la probabilité de l'utilisation par les patients des services d'urgence.

Résultats : La confiance des patients dans l'accès rapide à leur clinique fait tomber le taux d'utilisation du service des urgences $(\mathrm{OR}=0,73)$. Les sites ruraux offrent moins de services sans rendez-vous ou d'interventions médicales sur place, et la proximité des services de laboratoire et services diagnostiques est moindre mais, paradoxalement, les patients en milieu rural pensent avoir plus de chances dêtre vu par leur propre médecin en cas de maladie subite. Les patients de cliniques offrant une gamme plus large d'interventions médicales sur place rapportent une utilisation moindre de l'urgence ( $\mathrm{OR}=0.92$ par intervention). Les médecins en milieu rural tendent à diviser leur temps entre l'hôpital et les soins primaires; la pratique hospitalière fait augmenter l'utilisation de l'urgence par leurs patients $(\mathrm{OR}=1,64)$.

Discussion : Les patients de cliniques organisées dans le but d'améliorer la réponse aux soins urgents sont moins susceptibles d'utiliser l'urgence, en particulier dans les cliniques rurales. Bien que le taux élevé d'utilisation de l'urgence en milieu rural reflète en partie des problèmes d'accessibilité aux cliniques de soins primaires, dans un contexte de manque de ressources, l'urgence des hôpitaux ruraux pourraient couvrir à la fois les soins aigus de première ligne et les urgences médicales.

$\mathrm{I}$ N Canada, emergency room (ER) Crowding and Waiting times have long made headlines. The ER is the safety net for emergency health problems, the last resort for accessing care. High rates of ER use often indicate problems elsewhere in the system, ranging from inadequate management of clinical problems to problems with access for many reasons (Oster and Bindman 2003; Baer et al. 2001; Ansell et al. 2002; Noseworthy 2004; Canadian Association of Emergency Physicians and National Emergency Nurses Affiliation 2000; Rondeau and Francescutti 2005).

In 2002, we conducted a survey of Quebec primary healthcare users and found that $41 \%$ reported using the ER in the last year: $51 \%$ in rural and 33\% in urban areas (Haggerty et al. 2007). We postulated that higher rural ER use was unlikely to be due to a higher proportion of "real" emergencies and that a higher probability of rural ER use is related to inadequate accessibility or availability of primary care clinics. 
We undertook a secondary analysis of the data to determine whether accessibilityrelated organizational characteristics predict ER use and could explain observed differences between urban and rural areas.

\section{Method}

Our method, described elsewhere (Haggerty et al. 2007), is summarized here. The study was approved by the ethics review board of the Université de Montréal Hospital Research Centre. We believed that scarcity of healthcare resources was the defining feature of rural and remote areas. Rural clinics were those located in transport zones (approximately equivalent to census subdivisions) requiring more than one hour of travel to the nearest hospital offering subspecialty services and with fewer than four primary care clinics located within a 15-minute radius of the zone's centre. To link patients' experience to physician and clinic characteristics, we conducted a cross-sectional, multilevel survey of 100 primary care practice settings in Quebec between December 2001 and October 2002. Using random sampling within geographic and clinic-type strata in five health regions, we selected 60 private clinics and community health centres in urban and suburban areas and 40 in rural and remote areas. Within each, we selected up to four physicians and recruited 20 consecutive patients per physician in the waiting room prior to their consultation. Data collection days represented both scheduled and walk-in care.

\section{Information collected}

We collected information about patients' care experiences, physicians' practice profiles and clinic organization using self-administered questionnaires. Research technicians administering the study on site made observations and obtained information from front-desk staff about clinic organization, physician availability, time to third-next appointment (Institute for Healthcare Improvement 2005) and the physician's preferred modalities for coping with urgent care needs. Each practice director or administrator reported on physical and human resources, governance and management structures and operational links with other healthcare establishments. All participating physicians reported on their practice profile; they and the director reported on practice culture by rating the importance of such elements as rapid access for patients.

Patients' experience of accessibility was assessed using the "First-Contact Accessibility" scale of the Primary Care Assessment Tool (PCAT, French versions validated) (Cassady et al. 2000; Shi et al. 2001), which measures patients' confidence of being seen within one day in cases of sudden illness, and the "Organizational Accessibility" scale of the Primary Care Assessment Survey (Safran et al. 1998), in 
which patients rate the clinic's hours, wait times and telephone accessibility of office and physician. All questions relate to the patient's regular provider or clinic. In addition, $40 \%$ of respondents provided comments at the end of the questionnaire.

TABLE 1. Healthcare use, personal characteristics and experience of care of 2,725 patients reporting a study clinic as their usual source of care - comparing urban and rural areas

\begin{tabular}{|c|c|c|c|c|}
\hline & $\begin{array}{l}\text { Overall } \\
n=2725 \\
(100 \%)\end{array}$ & $\begin{array}{c}\text { Urban areas } \\
n=1506 \\
(55.3 \%)\end{array}$ & $\begin{array}{c}\text { Rural areas } \\
n=1219 \\
(44.7 \%)\end{array}$ & $\begin{array}{l}\text { Test value }(p) \\
\text { for urban-rural } \\
\text { difference }\end{array}$ \\
\hline \multicolumn{5}{|c|}{ Patient healthcare use in the past year } \\
\hline At least one ER visit & $\begin{array}{c}1117 \\
(41.0 \%)\end{array}$ & $490(32.5 \%)$ & $627(51.4 \%)$ & $\chi^{2}=99.5(<0.0001)$ \\
\hline \multicolumn{5}{|l|}{ Among users: } \\
\hline I-2 visits & $\begin{array}{c}750 \\
(67.1 \%)\end{array}$ & $373(76.1 \%)$ & 377 (60.1\%) & \multirow{2}{*}{$\chi^{2}=31.9(<0.0001)$} \\
\hline 3 or more visits & $\begin{array}{c}367 \\
(32.9 \%)\end{array}$ & $117(23.9 \%)$ & $250(39.9 \%)$ & \\
\hline $\begin{array}{l}\text { Mean number of primary care visits } \\
\text { Mean }( \pm S D)\end{array}$ & $\begin{array}{c}7.3 \\
( \pm 6.8)\end{array}$ & $6.8( \pm 6.8)$ & $7.8( \pm 6.6)$ & $t=3.70(0.0002)$ \\
\hline \multicolumn{5}{|l|}{ Personal characteristics } \\
\hline $\begin{array}{l}\text { Level of education } \\
\text { Percentage with secondary completed }\end{array}$ & $52.7 \%$ & $59.3 \%$ & $44.6 \%$ & $\chi^{2}=58.81(<0.0001)$ \\
\hline $\begin{array}{l}\text { Self-rated health status } \\
\text { Percentage rating poor or fair }\end{array}$ & $27.9 \%$ & $26.2 \%$ & $29.9 \%$ & $\chi^{2}=4.42(0.04)$ \\
\hline $\begin{array}{l}\text { Self-rated stress level } \\
\text { Percentage rating very to somewhat } \\
\text { stressful }\end{array}$ & $69.0 \%$ & $70.9 \%$ & $66.6 \%$ & $\chi^{2}=5.65(0.02)$ \\
\hline Mean age $( \pm S D)$ & $\begin{array}{c}51.6 \\
( \pm 18.3)\end{array}$ & $52.3( \pm 17.8)$ & $50.6( \pm 18.8)$ & $t=-2.45(0.01)$ \\
\hline \multicolumn{5}{|c|}{ Patient perceptions of primary care accessibility } \\
\hline $\begin{array}{l}\text { Confidence in being seen within a } \\
\text { day for a sudden illness } \\
\text { On nights and weekends } \\
\text { During working hours }\end{array}$ & $\begin{array}{l}13.6 \% \\
68.9 \%\end{array}$ & $\begin{array}{l}9.6 \% \\
72.5 \%\end{array}$ & $\begin{array}{l}18.6 \% \\
64.4 \%\end{array}$ & $\begin{array}{l}\chi^{2}=47.02(<0.0001) \\
\chi^{2}=20.69(<0.0001)\end{array}$ \\
\hline $\begin{array}{l}\text { Percentage rating elements of } \\
\text { organizational accessibility as ver } \\
\text { good or excellent } \\
\text { Waiting time to see doctor when sick } \\
\text { Capacity to speak to doctor over the } \\
\text { phone } \\
\text { Waiting time in doctor's office }\end{array}$ & $\begin{array}{l}41.2 \% \\
50.1 \% \\
50.2 \%\end{array}$ & $\begin{array}{l}47.7 \% \\
44.2 \% \\
45.7 \%\end{array}$ & $\begin{array}{l}56.6 \% \\
57.3 \% \\
58.2 \%\end{array}$ & $\begin{array}{l}\chi^{2}=17.01(<0.0001) \\
\chi^{2}=46.85(<0.0001) \\
\chi^{2}=57.07(<0.0001)\end{array}$ \\
\hline
\end{tabular}


Analysis

The main outcome was the probability of having used the ER in the last 12 months. Analysis was based only on patients whose regular source of care was the participating clinic. We described patient characteristics that might explain differences in ER use. We also explored whether their perceptions of clinic accessibility were associated with ER use. We attempted to build a multilevel logistic regression model that would explain clinic and physician characteristics associated with likelihood of ER use among sampled patients; all variable selections were driven by hypothesized associations with clinic or physician practice. For valid comparisons, all models controlled for patient age, education level, perceived health status and number of primary care visits in the previous year. We used the HLM multilevel software (Raudenbush et al. 2001), which takes into account the nesting of patients in physicians and of physicians in practice sites (Snijders and Bosker 1999). We looked for modification of clinic effects by urban and rural area.

Because organizational characteristics tend to be highly correlated (Contandriopoulos et al. 2001; Lamarche et al. 2003), it was often difficult to enter two related characteristics in the model. We ultimately selected variables that provided the most robust and global explanation of the phenomenon.

\section{Results}

Table 1 gives the characteristics, ER use and reported care experience of the 2,725 eligible patients. Likelihood and frequency of ER use are remarkably higher in rural than urban patients; use of primary care services is also slightly higher. Rural patients report less education and higher percentages of poor or fair health - factors reported among frequent ER users (CIHI 2005; Meng et al. 2006; Carrière 2004) - but these do not fully explain the observed differences in ER use. Paradoxically, rural patients provide higher ratings of their clinics' accessibility. Patients confident of rapid clinic access when ill were significantly less likely to have used the ER in the last year, compared to those who were not: odds ratios (ORs) were 0.78 (95\% CI: 0.64-0.97) in rural areas and 0.69 (95\% CI: 0.56-0.85) in urban areas.

The characteristics of the geographic areas where urban and rural clinics were located are described in Table 2. Clinic and physician characteristics that we hypothesized to be associated with accessibility also differed significantly between rural and urban areas (Table 3). While clinics did not differ on self-ratings of rapid-access culture, urban clinics showed a wider variation of opening hours, though none were open 24 hours day, 7 days a week, unlike community health centres in remote areas of Quebec. Most rural clinics (75\%) either had no walk-in services or offered them only during the day. Urban clinics were more likely to offer walk-in services over longer periods and to have specialists, radiology and laboratory services in immediate proximity. In contrast, most rural clinics (82.5\%) provided hospital care compared to $25 \%$ in 
urban areas, and rural physicians spent on average $70 \%$ of their time at the clinic compared to $90 \%$ among their urban counterparts. While more rural physicians worked at the ER, urban physicians tended to be more available at the clinic on evenings and weekends. Finally, rural physicians expressed greater attachment to the clinic's community than urban physicians.

TABLE 2. Geographic and service availability characteristics of urban and rural census subdivisions in which the study clinics were located

\begin{tabular}{|c|c|c|}
\hline & Urban $(n=60)$ & Rural $(n=40)$ \\
\hline \multirow[t]{2}{*}{ Number of municipalities (census subdivisions) } & 29 & 34 \\
\hline & $\begin{array}{l}\text { Mean ( } \pm \text { Standard } \\
\text { Deviation) }\end{array}$ & $\begin{array}{l}\text { Mean ( } \pm \text { Standard } \\
\text { Deviation) }\end{array}$ \\
\hline \multicolumn{3}{|l|}{ Geographic Characteristics } \\
\hline Average population density (persons / km²) & $2,261( \pm 2,035)$ & $251( \pm 326)$ \\
\hline $\begin{array}{l}\text { Average distance to nearest metropolitan centre } \\
\text { (Montreal or Quebec) in kilometres }\end{array}$ & $29( \pm 14)$ & $400( \pm 300)$ \\
\hline \multicolumn{3}{|l|}{ Service Availability' } \\
\hline $\begin{array}{l}\text { Average number of primary healthcare clinics within a I5-minute } \\
\text { transport route radius }{ }^{2}\end{array}$ & $136( \pm|5|)$ & $5( \pm 3)$ \\
\hline $\begin{array}{l}\text { Average number of primary healthcare clinics within a } 30 \text {-minute } \\
\text { transport radius }\end{array}$ & $413( \pm 186)$ & $8( \pm 12)$ \\
\hline $\begin{array}{l}\text { Average minutes travelled }{ }^{3} \text { to closest community hospital offering } \\
\text { basic services }\end{array}$ & $10( \pm 6)$ & $19( \pm 41)$ \\
\hline $\begin{array}{l}\text { Average minutes travelled }{ }^{3} \text { to closest referral hospital offering } \\
\text { subspecialty services }\end{array}$ & ||$( \pm 6)$ & $147( \pm 347)$ \\
\hline Average minutes travelled ${ }^{3}$ to closest tertiary care hospital & $19( \pm 10)$ & $330( \pm 430)$ \\
\hline
\end{tabular}

I Data provided by the Development and Information Service (SDI) of the Quebec Ministry of Health and Social Services (MSSSQ).

2 The transport radius is calculated from the centre of the municipality within the transport zone or the geographical centre of the transport zone in a metropolitan area.

3 The transport route is calculated from the centre of transport zone where the clinic is located to the centre of the nearest transport zone containing the health infrastructure of interest, expressed in the number of minutes required to cover the transport route by car on existing transportation networks. Data provided by the Quebec Ministry of Transport.

Table 4 shows which clinic and physician variables are significantly associated with the likelihood of ER use. Significant variables differ markedly between urban and rural settings. The only organizational variable associated with ER use in both settings was whether the clinic offered in-hospital follow-up. This increased the likelihood of ER use by 1.47 in urban and 1.57 in rural areas.

We tried to fit a single model (overall model, Table 5) with interaction terms between clinic factors and geographic location to account for expected effect modifi- 
cation by strata. After adjusting for age, health status, education and healthcare use, rural patients were almost five times more likely than urban patients to have used the ER in the last year. Only the interaction term for rapid-access culture approached statistical significance, suggesting that such a culture reduces likelihood of ER use in rural but not in urban areas. We consequently fitted separate models by geographic location (see Table 5).

TABLE 3. Characteristics of participating clinics and physicians - comparing urban and rural areas for elements hypothesized to predict clinic accessibility and likelihood of ER use

\begin{tabular}{|c|c|c|c|c|}
\hline Clinic Characteristics & $\begin{array}{l}\text { Overall } \\
n=100 \\
(100 \%)\end{array}$ & $\begin{array}{l}\text { Urban areas } \\
\qquad \begin{array}{l}n=60 \\
(60 \%)\end{array}\end{array}$ & $\begin{array}{l}\text { Rural areas } \\
\qquad \begin{array}{c}n=40 \\
(40 \%)\end{array}\end{array}$ & $\begin{array}{l}\text { Test value } \\
\text { (p) }\end{array}$ \\
\hline $\begin{array}{l}\text { Practice culture: mean importance } \\
\text { given to rapid access (scale of I to 5) } \\
\text { ( } \pm \text { SD) }\end{array}$ & $4.0( \pm 0.7)$ & $4.0( \pm 0.7)$ & $4.0( \pm 0.8)$ & $\begin{array}{c}t=-0.53 \\
(0.6)\end{array}$ \\
\hline $\begin{array}{l}\text { Opening hours per week (percent) } \\
\text { Less than } 30 \text { hours } \\
31 \text { to } 40 \text { hours } \\
41 \text { to } 50 \text { hours } \\
51 \text { to } 60 \text { hours } \\
61 \text { to } 90 \text { hours } \\
\text { Open } 24 \text { hours } 7 \text { days a week }\end{array}$ & $\begin{array}{c}6.0 \% \\
23.0 \% \\
36.0 \% \\
15.0 \% \\
17.0 \% \\
3.0 \%\end{array}$ & $\begin{array}{c}6.7 \% \\
18.3 \% \\
31.7 \% \\
20.0 \% \\
23.3 \% \\
0 \%\end{array}$ & $\begin{array}{c}5.0 \% \\
30.0 \% \\
42.5 \% \\
7.5 \% \\
7.5 \% \\
7.5 \%\end{array}$ & $\begin{array}{c}\chi^{2}=12.9 \\
(0.03)\end{array}$ \\
\hline $\begin{array}{l}\text { Percentage offering walk-in services } \\
\text { Days, evenings and weekends } \\
\text { Days and evenings } \\
\text { Daytime only } \\
\text { None }\end{array}$ & $\begin{array}{l}27.0 \% \\
11.0 \% \\
36.0 \% \\
26.0 \%\end{array}$ & $\begin{array}{l}33.3 \% \\
13.3 \% \\
31.7 \% \\
21.7 \%\end{array}$ & $\begin{array}{l}17.5 \% \\
7.5 \% \\
42.5 \% \\
32.5 \%\end{array}$ & $\chi^{2}=4.8(0.2)$ \\
\hline $\begin{array}{l}\text { Percentage offering hospital in-patient } \\
\text { follow-up to patients }\end{array}$ & $48.0 \%$ & $25.0 \%$ & $82.5 \%$ & $\begin{array}{l}\chi^{2}=31.8 \\
(<0.0001)\end{array}$ \\
\hline $\begin{array}{l}\text { Level of technical support available at } \\
\text { the clinic: } \\
\text { Mean number of medical procedures avail- } \\
\text { able on site (out of } 14)^{5}( \pm S D)\end{array}$ & $2.7( \pm 1.7)$ & $2.8( \pm 1.7)$ & $2.6( \pm 1.6)$ & $t=-0.7(0.5)$ \\
\hline Presence of specialists on site & $43.0 \%$ & $63.3 \%$ & $12.5 \%$ & $\begin{array}{l}\chi^{2}=25.3 \\
(<0.0001)\end{array}$ \\
\hline Radiology services on site & $25.0 \%$ & $35.0 \%$ & $10.0 \%$ & $\begin{array}{c}\chi^{2}=8.0 \\
(0.005)\end{array}$ \\
\hline Laboratory services on site & $35.0 \%$ & $51.7 \%$ & $10.0 \%$ & $\begin{array}{l}\chi^{2}=18.3 \\
(<0.0001)\end{array}$ \\
\hline $\begin{array}{l}\text { Average number of formal and opera- } \\
\text { tional links with other healthcare } \\
\text { establishments ( } \pm \text { SD) }\end{array}$ & $1.0( \pm 1.3)$ & $0.6( \pm 1.0)$ & $1.7( \pm 1.3)$ & $\begin{array}{l}t=4.58 \\
(<0.0001)\end{array}$ \\
\hline $\begin{array}{l}\text { Average number of family physicians } \\
\text { per clinic }( \pm \text { SD) }\end{array}$ & $5.8(4.4)$ & $5.3(4.2)$ & $3.6(3.2)$ & $\begin{array}{c}t=2.43 \\
(0.02)\end{array}$ \\
\hline
\end{tabular}


TABLE 3. Continued

\begin{tabular}{|c|c|c|c|c|}
\hline Physician characteristics & $\begin{array}{l}\text { Overall } \\
n=215 \\
(100 \%)\end{array}$ & $\begin{array}{c}\text { Urban areas } \\
n=127 \\
(59.1 \%)\end{array}$ & $\begin{array}{l}\text { Rural areas } \\
n=88 \\
(40.9 \%)\end{array}$ & $\begin{array}{l}\text { Test value } \\
\text { (p) }\end{array}$ \\
\hline $\begin{array}{l}\text { Days to } 3 \text { rd next available } \\
\text { appointment } \\
\text { Mean }( \pm S D)\end{array}$ & $23.8( \pm 21.9)$ & $25.0( \pm 25.0)$ & $22.1( \pm 16.4)$ & $\begin{aligned} t & =-1.02 \\
& (0.3)\end{aligned}$ \\
\hline $\begin{array}{l}\text { Availability at the clinic } \\
\text { Evenings } \\
\text { Weekends }\end{array}$ & $\begin{array}{l}29.3 \% \\
20.8 \%\end{array}$ & $\begin{array}{l}36.2 \% \\
23.6 \%\end{array}$ & $\begin{array}{l}19.3 \% \\
15.9 \%\end{array}$ & $\begin{array}{c}\chi^{2}=9.2 \\
(0.009) \\
\chi^{2}=3.1(0.2)\end{array}$ \\
\hline \multicolumn{5}{|l|}{$\begin{array}{l}\text { Distribution of time spent in various } \\
\text { settings }\end{array}$} \\
\hline $\begin{array}{l}\text { Mean number of clinical hours per week } \\
( \pm \mathrm{SD})\end{array}$ & $47.5( \pm \mid 8.7)$ & $44.9( \pm 17.6)$ & $51.3( \pm 19.7)$ & $\begin{array}{l}t=2.5 \\
(0.01)\end{array}$ \\
\hline $\begin{array}{l}\text { Mean percentage of time in primary care } \\
\text { clinic } \\
\text { Mean }( \pm S D)\end{array}$ & $82.1( \pm 23.2)$ & $90.3( \pm 17.6)$ & $70.3( \pm 25.1)$ & $\begin{array}{l}t=-6.44 \\
(<0.0001)\end{array}$ \\
\hline $\begin{array}{l}\text { Mean percentage of time in hospital } \\
\text { in-patient care } \\
\text { Mean }( \pm \text { SD) }\end{array}$ & $9.7( \pm 16.1)$ & $4.4( \pm 12.0)$ & $17.4( \pm \mid 8.0)$ & $\begin{array}{l}t=5.9 \\
(<0.0001)\end{array}$ \\
\hline $\begin{array}{l}\text { Mean percentage of time in ER } \\
\text { Mean }( \pm S D)\end{array}$ & $5.1( \pm 15.4)$ & $0.8( \pm 4.8)$ & $11.2( \pm 22.0)$ & $\begin{array}{l}t=4.3 \\
(<0.000 I)\end{array}$ \\
\hline $\begin{array}{l}\text { Distribution of percentage of time } \\
\text { spent in walk-in services per week } \\
\text { None } \\
>0-<25 \\
25-<50 \\
50 \text { or more }\end{array}$ & $\begin{array}{l}36.7 \% \\
25.6 \% \\
15.8 \% \\
21.9 \%\end{array}$ & $\begin{array}{l}35.4 \% \\
15.0 \% \\
20.5 \% \\
29.1 \%\end{array}$ & $\begin{array}{l}38.6 \% \\
40.9 \% \\
9.1 \% \\
11.4 \%\end{array}$ & $\begin{array}{l}\chi^{2}=25.6 \\
(<0.0001)\end{array}$ \\
\hline $\begin{array}{l}\text { Mean attachment to the community } \\
\text { served by the clinic (scale I to } 7 \text { ) } \\
\text { Mean }( \pm \text { SD) }\end{array}$ & $5.7( \pm 1.0)$ & $5.5( \pm 1.0)$ & $5.9( \pm 0.9)$ & $2.63(0.009)$ \\
\hline
\end{tabular}

4 These are community health centres (Centres de santé) found only in remote areas that have integrated emergency rooms and 10- to 15-bed capacity to admit patients for observation or testing. The facility is open 24 hours a day, 7 days a week.

5 Audiometry, refraction, ECG interpretation, pulmonary function testing, Pap smears, IUD insertion, D+C aspiration, lumbar puncture, musculoskeletal (includes joint) injection/aspiration, casting/splinting, anoscopy, needle aspiration (for diagnosis/biopsy), skin biopsy, suturing

Only two variables predicted urban ER use: offering in-patient follow-up $(\mathrm{OR}=1.64)$ and offering a wider range of procedures on site $(\mathrm{OR}=0.92$ per additional procedure, compared to the mean). Rural models were more complex to build because significant organizational variables tended to be highly correlated and could not be entered together. For instance, correlation between rapid-access culture and number of procedures available was 0.34 . Indeed, correlations between a practice culture of rapid access and key accessibility variables such as availability on evenings and week- 
Features of Primary Healthcare Clinics Associated with

Patients' Utilization of Emergency Rooms

TABLE 4. Clinic and physician characteristics significantly associated with likelihood of ER use by clinic patients. Results show odds ratio of ER use after controlling for patient age, level of education, self-rated health status and number of primary care visits in the last year (confidence intervals are provided only for statistically significant or suggestive findings)

\begin{tabular}{|c|c|c|c|}
\hline Clinic Characteristics & $\begin{array}{l}\text { Overall } \\
n=2725\end{array}$ & $\begin{array}{l}\text { Urban areas } \\
n=1506\end{array}$ & $\begin{array}{l}\text { Rural areas } \\
n=1219\end{array}$ \\
\hline Opening hours & । & । & । \\
\hline $\begin{array}{l}\text { Clinic offers walk-in services: } \\
\text { Days, evenings and weekends } \\
\text { Days and evenings } \\
\text { Daytime only } \\
\text { None (reference) }\end{array}$ & $\begin{array}{c}1 \\
0.71(0.48-10.6) \\
0.78(0.59-1.02) \\
-\end{array}$ & 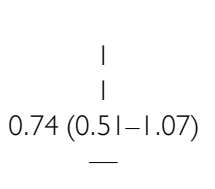 & $\begin{array}{c}0.54(0.30-0.98) \\
0.55(0.30-1.04) \\
1 \\
-\end{array}$ \\
\hline $\begin{array}{l}\text { Clinic offers in-hospital follow-up to patients } \\
\text { (compared to none offered) }\end{array}$ & $1.53(1.15-2.04)$ & $1.47(1.04-2.07)$ & $1.57(0.95-2.58)$ \\
\hline $\begin{array}{l}\text { Level of technical support available at the } \\
\text { clinic: } \\
\text { Medical procedures available on site (effect of each } \\
\text { procedure relative to the mean of } 2.7 \text { out of } 14 \text { ) }\end{array}$ & $0.93(0.86-1.01)$ & I & $0.88(0.77-1.01)$ \\
\hline Presence of specialists on site & । & । & । \\
\hline Radiology services on site & । & । & । \\
\hline Laboratory services on site & । & । & । \\
\hline $\begin{array}{l}\text { Number of formal and operational links with } \\
\text { other healthcare establishments }\end{array}$ & I & I & I \\
\hline $\begin{array}{l}\text { Practice culture: importance given to rapid } \\
\text { access (effect of each unit of importance rela- } \\
\text { tive the mean of } 4 \text { ) }\end{array}$ & $0.85(0.7 \mid-1.01)$ & I & $0.77(0.61-0.97)$ \\
\hline Physician Characteristics & $\begin{array}{c}\text { Overall } \\
n=2677\end{array}$ & $\begin{array}{l}\text { Urban areas } \\
n=1473\end{array}$ & $\begin{array}{l}\text { Rural areas } \\
n=1204\end{array}$ \\
\hline Days to 3 rd next available appointment & । & । & । \\
\hline $\begin{array}{l}\text { Physician availability at the clinic: } \\
\text { Evenings } \\
\text { Weekends }\end{array}$ & $\begin{array}{c}1 \\
0.77(0.61-0.96)\end{array}$ & 1 & $\begin{array}{l}0.59(0.41-0.85) \\
0.59(0.46-0.76)\end{array}$ \\
\hline \multicolumn{4}{|l|}{ Time spent in various settings: } \\
\hline $\begin{array}{l}\text { Percentage of time spent in primary care: } \\
<50 \\
50-<70 \\
70-<90 \\
\geq 90 \text { (reference) }\end{array}$ & $\begin{array}{c}1.41(1.06-1.9) \\
1 \\
1 \\
-\end{array}$ & $\begin{array}{r}1 \\
1 \\
1 \\
-\end{array}$ & $\begin{array}{c}1.72(1.17-2.53) \\
1 \\
1 \\
-\end{array}$ \\
\hline Percentage of time spent in hospital in-patient care & $1.01(1.00-1.02)$ & । & $1.01(1.00-1.02)$ \\
\hline Percentage of time spent in ER & । & । & । \\
\hline
\end{tabular}


TABLE 4. Continued

\begin{tabular}{|l|c|c|c|}
\hline $\begin{array}{l}\text { Distribution of percentage of time spent in } \\
\text { walk-in services per week: }\end{array}$ & & \\
$\begin{array}{l}\text { None (reference) } \\
>0-<25\end{array}$ & - & - & - \\
$25-<50$ & 1 & 1 & $0.67(0.45-1.00)$ \\
$\geq 50$ & $0.77(0.59-0.99)$ & 1 & $0.69(0.50-0.96)$ \\
\hline $\begin{array}{l}\text { Attachment to the community served by the } \\
\text { clinic (scale I to 7) }\end{array}$ & $0.90(0.79-1.02)$ & 1 & $0.81(0.67-0.97)$ \\
\hline
\end{tabular}

ends are stronger in rural than in urban clinics (data available on request). Our final model includes the variable of rapid-access culture, which we considered foundational in determining the clinic's organizational features. The mean importance attached to rapid access in clinics was 3.97 (on a scale of 1 to 5). In clinics that rated the importance of rapid access at 5 , patients were $22 \%$ less likely to use the $E R(O R=0.78)$. If their clinic also offered evening walk-in services, likelihood of ER use was $23 \%$ less than among patients of clinics that did not $(\mathrm{OR}=0.77)$. However, if their physician's working time at the clinic was less than $50 \%$, likelihood of ER use was $47 \%$ higher $(\mathrm{OR}=1.47)$ compared to patients of physicians spending $90 \%$ of their time on site.

\section{Discussion}

This study highlights not only the large difference in ER use between urban and rural primary healthcare clients, but also differences in primary care organization. Rural clinics have fewer accessibility-related features, and rural physicians spend less time at their clinics and offer less walk-in care (even though they work longer hours, overall). These factors reduce rapid-response capacity for urgent problems, which may partly account for higher rural ER use, especially since there are considerably fewer primary care alternatives in rural areas. When the usual clinic is not readily available, the ER may be the principal alternative for both minor and major urgent care needs. Lower clinical severity scores among rural ER users are found in Ontario (CIHI 2005), supporting the possibility that rural hospital ERs may be filling a primary care role in rural areas. Our interpretations should be accepted with caution because they are based on secondary analysis of data collected for another objective, and our findings are predicated on the assumption, which we had no way of testing, that higher ER use in rural areas does not reflect "true" emergencies.

We found that when the clinic physicians also provide in-hospital services, their patients are more likely to use the ER. Again, this finding may be due to lower clinic accessibility and/or to a higher probability of patients' seeing their own physician in the ER. In rural areas, the ER can provide both continuity of care and accessible services.

We found that patients' confidence in being seen rapidly at their clinic for sudden 
illness decreases their likelihood of using the ER, but rural patients expressed higher confidence levels than their urban counterparts. This paradox may be explained by the fact that more rural physicians work in the local hospital. Clinic secretaries reported that almost a quarter of rural physicians managed urgent care for their regular patients by meeting them at the ER, whereas this situation was rare in urban areas. Rural patients and physicians also tend to belong to the same community network, and rural patients may know where to find their doctor, including at the ER, hence their confidence in being seen rapidly and their tendency to use the ER. This interpretation would need to be explored in future studies.

TABLE 5. Final logistic regression models of clinic and physician characteristics associated with likelihood of ER use in clinic patients. Results show odds ratio of ER use, controlling for other variables in the model including clinic case mix, patient age, level of education, self-rated health status and number of primary care visits in the last year

\begin{tabular}{|l|c|c|}
\hline & Odds ratio & $\mathbf{9 5 \%} \mathbf{~ C l}$ \\
\hline Overall Model (2,677 patients) & & \\
\hline Rural location & 4.74 & $1.78-12.60$ \\
\hline Number of medical procedures on site & 0.92 & $0.85-1.00$ \\
\hline Interaction term between rapid-access culture and rural location & 0.80 & $0.63-1.02$ \\
\hline Urban Model (I,473 patients) & & \\
\hline Offering in-patient follow-up & 1.64 & $1.11-2.41$ \\
\hline Number of medical procedures on site & 0.92 & $0.82-1.00$ \\
\hline Rural Model (1,204 patients) & & \\
\hline Culture of rapid access & 0.78 & $0.64-0.96$ \\
\hline Availability of evening walk-in services & 0.77 & $0.58-1.03$ \\
\hline $\begin{array}{l}\text { Physician time spent in primary care site less than 50\% } \\
\text { (reference } \geq 90 \%)\end{array}$ & 1.47 & $1.01-2.14$ \\
\hline
\end{tabular}

These findings call for prudence in interpreting high or repeated ER use as an indicator of poor control of health problems (Oster and Bindman 2003; Ansell et al. 2002). Our study suggests ER use is more common in rural areas and may not constitute an ambulatory-care-sensitive indicator in studies using provincewide administrative data. Rather, it is possible the ER intentionally fulfills a slightly different function in rural areas, attending to both emergency and urgent primary care. Likewise, primary care clinics may fulfill a slightly different function, seemingly more oriented towards continuity and follow-up than acute episodic care, which is consistent with lower 
patient volume and fewer procedures on site. The rural ER may be more integrated with the primary healthcare system, with physicians being the principal agents of integration through involvement in both areas.

Still, high rural ER use is not necessarily alarm-free. Our study reinforces the association between poor primary care accessibility and ER use. And in rural areas with fewer alternatives, patients are very dependent on clinic organizational structures and their physician's practice style. Rural physicians may need to enhance their community practice accessibility or integrate more formally and transparently with the ER for walk-in care. In the open comments, patients expressed strong preferences to be seen by their own physician at their own clinic rather than going to the ER. Using the ER for acute and episodic care may indeed be an efficient way to organize scarce resources in rural and remote areas, but it should be part of a clear policy that maximizes efforts by both patients and health professionals.

This study reinforces the notion that ER utilization is associated with problematic primary healthcare accessibility for urgent needs, especially in rural contexts where there are fewer primary care alternatives. However, it also provokes reflection on an expanded function of rural ERs and cautions against monolithic interpretation of ER rates. In a 2004 five-country Commonwealth survey, Canada had the highest ER utilization rate (Schoen et al. 2004). A high rate of non-urgent ER use is interpreted as an indicator of primary care system failure (Afilalo et al. 2004; McGill 1994), and the clear message is that primary healthcare accessibility in Canada must be enhanced, including appropriate integration with the ER in rural and remote areas.

Correspondence may be directed to: Jeannie Haggerty, Associate professor and Canada Research Chair, Département de Sciences de la santé communautaire, Université de Sherbrooke, Complexe St-Charles, bureau 354, tour Est, 1111, rue St-Charles Ouest, Longueuil (Québec) J4K 5G4, Canada. Tél. : 450-466-5000 ext. 3682. Fax : 450-651-6589. Email : jeannie. haggerty@usherbrooke.ca.

\section{REFERENCES}

Afilalo, J., A. Marinovich, M. Afilalo et al. 2004. "Non-Urgent Emergency Department Patient Characteristics and Barriers to Primary Care." Academic Emergency Medicine 11: 1302-10.

Ansell, D., R. Schiff, D. Goldberg, A. Furumoto-Dawson, S. Dick and C. Peterson. 2002."Primary Care Access Decreases Non-Urgent Hospital Visits for Indigent Diabetics." Journal of Health Care for the Poor and Underserved 13: 171-83.

Baer, R.B., J.S. Pasternack and F.L. Zwemer Jr. 2001."Recently Discharged In-patients as a Source of Emergency Department Overcrowding." Academic Emergency Medicine 8: 1091-94.

Canadian Association of Emergency Physicians and National Emergency Nurses Affiliation. 2000.

“Position Statement - Emergency Department Overcrowding, 2000." Retrieved September 26, 2007. <http://caep.ca/template.asp?id=1d7c8feb2a7c4a939e4c2fe16d654e39>. 


\section{Features of Primary Healthcare Clinics Associated with Patients' Utilization of Emergency Rooms}

Canadian Institute for Health Information (CIHI). 2005. Understanding Emergency Department Wait Times: Who Is Using Emergency Departments and How Long Are They Waiting? Ottawa: Author.

Carrière, G. 2004. "Use of Hospital Emergency Rooms." Health Reports 16: 35-39.

Cassady, C.E., B. Starfield, M.P. Hurtado, R.A. Berk, J.P. Nanda and L.A. Friedenberg. 2000.

“Measuring Consumer Experiences with Primary Care." Pediatrics 105(4): 998-1003.

Contandriopoulos, A.P., J.L. Denis, N. Touati and R. Rodriguez. 2001. “Intégration des soins: dimensions et mise en oeuvre." Ruptures, revue transdiciplinaire en santé 8: 38-52.

Haggerty, J.L., R. Pineault, M-D. Beaulieu et al. 2007. "Room for Improvement: Patient Experience of Primary Care in Quebec Prior to Major Reforms." Canadian Family Physician 53: $1056-57$.

Institute for Healthcare Improvement. 2005. Measures: Primary Care Access. “Third Next Available Appointment." Retrieved September 26, 2007. <http://www.ihi.org/IHI/Topics/OfficePractices/ Access/Measures/Third+Next+Available+Appointment.htm $>$.

Lamarche, P.A., M-D. Beaulieu, R. Pineault, A-P. Contandriopoulos, J-L. Denis and J. Haggerty. 2003. Choices for Change: The Path for Restructuring Primary Healthcare Services in Canada. Ottawa: Canadian Health Services Research Foundation.

McGill, J.M. 1994. "Non-Urgent Use of the Emergency Department: Appropriate or Not?" Annals of Emergency Medicine 24: 953-57.

Meng, Y.Y., S.H. Babey, E.R. Brown et al. 2006."Emergency Department Visits for Asthma: The Role of Frequent Symptoms and Delay in Care." [See comment]. Annals of Allergy, Asthma, and Immunology 96: 291-97.

Noseworthy, S.B. 2004. “Emergency Department Overcrowding: Waiting for Disaster." Outlook 27: 12-17.

Oster, A. and A.B. Bindman. 2003. "Emergency Department Visits for Ambulatory Care Sensitive Conditions: Insights into Preventable Hospitalizations." [See comment]. Medical Care 41: 198207.

Raudenbush, S.W., A.S. Byrk, Y.F. Cheong and R. Congdon. 2001. HLM 5: Hierarchical Linear and Nonlinear Modeling, Version 5. Lincolnwood, IL: Scientific Software International.

Rondeau, K.V. and L.H. Francescutti. 2005. "Emergency Department Overcrowding: The Impact of Resource Scarcity on Physician Job Satisfaction." Journal of Healthcare Management 50: 327-42. Safran, D.G., J. Kosinski, A.R. Tarlov, W.J. Rogers, D.A. Taira, N. Leiberman and J.E. Ware. 1998. "The Primary Care Assessment Survey: Test of Data Quality and Measurement Performance." Medical Care 36(5): 728-39.

Schoen, C., R. Osborn, P.T. Huynh et al. 2004."Primary Care and Health System Performance: Adults' Experiences in Five Countries." Health Affairs 1037: 487-503.

Shi, L., B. Starfield and J. Xu. 2001. "Validating the Adult Primary Care Assessment Tool." Journal of Family Practice 50: n161w-n171w.

Snijders, T. and R. Bosker. 1999. Multi-level Analysis: An Introduction to Basic and Advanced Multilevel Modeling. London, UK: Sage Publications. 